\title{
FILOSOFIA E PSICANÁLISE A QUESTÃO DA ALTERIDADE EM LACAN E LEVINAS
}

\author{
Luiz Carlos Santuário*
}

SÍNTESE - O tema da alteridade é caro a ambos os autores. Contudo, a tematização da especificidade desta alteridade é dissimétrica em cada autor. Em Levinas, o privilégio é concedido à presença originária do outro, enquanto produtor de um trauma desorganizante original para a produção do eu e da própria relação com o outro. Por seu lado, para a psicanálise de Lacan, a relação mais originária do sujeito é com o símbolo, na medida em que o autor reivindica a anterioridade originária da ordem simbólica que opera como conditio sine qua non da assunção da subjetividade.

PALAVRAS-CHAVE - Filosofia. Psicanálise. Levinas. Lacan. Alteridade. Simbólico.
ABSTRACT - The issue of othemess is dear to both authors. However, their explanations of such a phenomenon differ markedly. In Levinas, precedence is given to the presence of the other as being that on which, by way of its generating a fundamental disorganizing trauma, the origin of both the self and its relationship with the other ultimately depends. Lacanian psychoanalysis, for its part, puts forward the view according to which the subject is ultimately generated by its relationship with the symbol, insofar as, for Lacan, the symbolic order takes precedence in the process leading to one's assumption of his own subjectivity.

KEY WORDS - Philosophy. Psychoanalysis. Levinas. Lacan. Othemess. Symbolic.

\section{A alteridade em Levinas}

O projeto filosófico de Emmanuel Levinas, em suas linhas gerais, pode ser assim compreendido:

a) 'Sua preocupação principal é delinear uma ética do 'face a face' na relação com o Outro, o qual, enquanto imediato e singular, não é nenhum transcendente. Buscando tal possibilidade o autor é levado aos 'limites da fenomenologia', e a criticar muitos filósofos anteriores por suas preocupações com a ontologia."1

b) Considerado "o grande moralista do pensamento contemporâneo, com reflexões atravessadas pelo elogio do pluralismo e da diferença e em contínua polêmica com os totalitarismos de cunho hegeliano". ${ }^{2}$

* Doutorando em Filosofia na Pontifícia Universidade Católica do Rio Grande do Sul (PUCRS).

1 HONDERICH, T. (ed.) The Oxford Companion to Philosophy. Oxford/New York: Oxford University Press, 1995, p. 481 (Tradução de LCS).

2 BONI, Lamberto (ed.). Enciclopedia de la filosofia Garzanti. Barcelona: BSA, 1992, p. 573.

3 Tbidem.

\begin{tabular}{|l|c|l|l|l|l|}
\hline VERITAS & Porto Alegre & v. 44 & n. 2 & Junho 1999 & p. 369-374 \\
\hline
\end{tabular}


c) 'O 'platonismo' de Levinas é essa tentativa de ruptura com a caverna do próprio eu para abrir-se ao reconhecimento do estranho no próximo."3

d) "Levinas efetivamente quer construir uma alternativa ao pensamento em filosofia. ${ }^{4}$ Sua trajetória conduz, ele argumenta, para longe da ontologia, epistemologia, ou racionalidade, para um ponto onde a alteridade é confrontada em toda sua 'nudidade' (para usar um termo caro a Levinas) - a um ponto onde sua irredutibilidade possa ser reconhecida." 5

A partir destas breves mas significativas indicações é possível apreender-se as principais linhas que ocupam as reflexões do autor. Nesta sua tentativa de produzir uma Aufhebung da filosofia tradicional, o autor insiste em que nossa relação ontológica fundamental não é com o intelecto, com a atividade de representação, mas com nossa condição de encarnados no mundo, por conseguinte, com o outro, em sua existência concreta. Desta forma, a própria compreensibilidade da existência é derivada da originária relação com a alteridade.

Levinas apela para o simples e singelo fato da pura existência, enquanto metalinguagem de si mesma. Assim, "contingência e facticidade podem ser compreendidos e concebidos sem recurso à intelecção". ${ }^{6}$

$\mathrm{O}$ autor estaria procedendo a uma abducção da ontologia transcendental heideggeriana, da descrição do modus do ser-no-mundo, a favor de uma filosofia engajada. ${ }^{7}$ Tornar-se-iam desimportantes aqui as sofisticadas descrições fenomenológicas heideggerianas que procuram circunscrever o fenômeno da compreensão, do pré-compreensivo, uma vez que o compreender não é um ato de intelecção, mas "compreender é relacionar-se ao particular..."

$\mathrm{O}$ absolutamente fundante é a presença fáctica do outro e não o elemento categorial ou conceitual que circunscreveria este outro para mim, pois "na nossa relação com outrem, este não nos afeta a partir de um conceito. Ele é ente e conta como tal". 9

Levinas parece querer independentizar a presença e, por conseguinte, o significado da presença do outro, de qualquer ato de compreensão intelectual, abstrata, representacional, insistindo em extrair da pura presença do outro o único significado plausivel para o fato de sua existência, que, a partir disto, opera no patamar da pura invocação. Isto é, sou convocado a interagir com outrem, não enquanto algo representado, mas como fato de pura presença. ${ }^{10}$

Desta forma, para o filósofo, "o homem é o único ser que não posso encontrar sem lhe exprimir este encontro mesmo", ${ }^{11}$ pois o vínculo com outrem não se reduz à representação de outrem, mas à sua invocação. ${ }^{12}$

4 Wants to bypass thought in philosophy (no original).

5 LECHTE, John. Fifty Key contemporary thinkers. London/New York: Oxford University Press, 1995, p. 117 (Tradução de LCS).

6 LÉVINAS, E. Ensaios sobre a alteridade. Petrópolis: Vozes, 1997, p. 22 (Coord. da tradução: P. Pivatto).

7 Id., ibid.

8 Id., p. 26

9 Id., ibid.

10 Id., p. 27.

11 Id., p. 28

12 Id., p. 29 
O absolutamente outro é a outra pessoa (autrul). ${ }^{13}$ A nudeza ${ }^{14}$ do outro é aquilo que me invoca...desde ela mesma e não desde um sistema. ${ }^{15} \mathrm{O}$ que tornase absolutamente indispensável é a afirmação da prioridade da relação a outrem, ${ }^{16}$ e a necessidade de denunciar e abolir todo pensamento totalitário, pois no sistema o homem (e seu rosto) não aparecem.

No sistema, não há lugar para "o temor que me vem do rosto do outro que, através da sua súplica, me invoca" ${ }^{17}$ Em vista disto, é indispensável conservar a distância em relação à atitude meramente gnosiológica, uma vez que o efetivamente importante é o "despertar para o outro homem, que não é saber". ${ }^{18}$

O pensamento de Levinas confere uma reflexão especial ao estatuto da linguagem. Se o outro (autrul) deve aparecer para mim, a partir de sua invocação, como rosto e não como categoria da intelecção, a linguagem não deveria ser utilizada para recompor a colcha estraçalhada das categorias do pensamento, como faria a filosofia ortodoxa, mas sim deve ser utilizada para responder à invocação da presença do rosto do outro.

Desta forma, na filosofia levinasiana "têm-se o direito de perguntar se a linguagem não está fundada numa relação anterior à compreensão e que constitui a razão". ${ }^{19}$ Em Levinas, "trata-se de perceber a função da linguagem não como subordinada à consciência que se toma da presença de outrem ou de sua vizinhança ou da comunidade com ele, mas como condição desta 'tomada de consciência'."20

A partir da reconstrução feita acima, parece haver uma abdicação, em Levinas, de qualquer nível ou instância de metalinguagem para pensar e compreender o fato, o dado e o outro. Em função da prioridade concedida por Levinas a termos como: relação - invocação - rosto - outrem -, o discurso levinasiano poderia ser compreendido como uma atitude de neo-socratismo, a partir da ambição de ocupar uma posição socrática, mas não a partir da disputa metodológica em torno da ilegitimidade das doxas proferidas mas a partir da denúncia do artificialismo da disputatio meramente verbal.

\section{A alteridade em Lacan}

Diversamente da linearidade fenomenológica levinasiana, a predicação estruturalista operada na reconstrução do edifício freudiano, empreendida pelo psicanalista francês Jacques-Marie Lacan sustenta que a questão da alteridade deve ser compreendida em relação a dois conceitos fundamentais: outro (chamado também outro minúsculo) e Outro (também chamado grande outro, equivale à ordem simbólica). Outro é o lugar do significante, equivale ao lugar a quem se dirige o discurso do sujeito e de quem o sujeito recebe sua mensagem de forma invertida.

13 LECHTE, John. Fifty key contemporary thinkers. London/New York: Oxford University Press, 1995, p. 117 (tradução LCS).

14 Nudity (no original).

15 Id., ibid.

16 Cf. Lévinas, op. cit., p. 166.

17 Id., p. 174.

18 Id., p. 216.

19 Id., p. 25.

20 Id., p. 27. 
A relação do sujeito, necessariamente intransparente a si mesmo, por ter seu surgimento, aparecimento e nascimento datado de seu encontro (traumático) com a linguagem (ordem simbólica).

"Outro como o lugar onde a psicanálise situa, além do parceiro imaginário, aquilo que, anterior e exterior ao sujeito, não obstante o determina."21

"A concepção lacaniana do significante implica uma relação estrutural entre o desejo e o 'grande Outro'. Essa noção de 'grande Outro' é concebida como um espaço aberto de significantes que o sujeito encontra desde seu ingresso no mundo." 22

Esse Outro é equivalente à ordem simbólica, isto é, aquilo que operou para mim enquanto condição de possibilidade do aparecimento de minha própria subjetividade. ${ }^{23}$

"O Outro é aquilo diante do qual vocês se fazem reconhecer. Mas vocês só podem se fazer reconhecer por ele porque ele é em primeiro lugar reconhecido. Ele deve ser reconhecido para que vocês possam fazer-se reconhecer."24

Para Lacan, a ordem simbólica merece ser compreendida como tendo status de uma segunda natureza e momento propriamente instituidor do modo específico do humano-ser.

A ordem simbólica deve ser concebida como alguma coisa de superposto, e sem o que não haveria vida animal possivel para esse sujeito estrambólico que é o homem.

O projeto lacaniano aponta inexoravelmente para o desvelamento da "excentricidade radical de si em si mesmo com que o homem é defrontado" pela verdade descoberta por Freud da divisão do homem, da Spaltung. ${ }^{25}$ Lacan mostra assim a "heteronomia radical cuja hiância no homem foi mostrada pela descoberta de Freud". 26

A psicanálise de Lacan alerta que "a heteronomia é simplesmente desconhecida quando é reduzida a qualquer 'sentimento do outro',"27 pois haveria um o(O)utro a quem eu estaria mais "apegado do que a mim mesmo, já que, no seio mais consentido de minha identidade comigo mesmo, é ele que me agita". ${ }^{28}$

\section{Lacan e Levinas: abordagens dissimétricas do tema da alteridade}

Uma primeira aproximação à questão da alteridade em Lacan e Levinas pressupõe a compreensão de que se tratam de campos teóricos dissimétricos, por operarem a partir de premissas conflitantes.

21 CHEMAMA, R. (org.). Dicionánio de psicanálise. Porto Alegre: Artes Médicas, 1995, p. 156.

22 KAUFMANN, P. Dicionário enciclopédico de psicanálise. Rio de Janeiro: Zahar, 1996, p. 386.

23 LACAN, Jacques. Écrits. Paris: Seuil, 1966, p. 529.

24 LACAN, Jacques. Le Seminaire. Livre III, p. 62.

25 LACAN, Jacques. Écrits. Paris: Seuil, 1966, p. 528.

26 Id., ibid.

27 Id., p. 530.

28 Id., p. 528. 
Em Levinas existe aparentemente a tentativa de elevar o tema da alteridade ao estatuto da (absoluta) transparência do outro, do semelhante, ao dizer que "em nossa relação com o outro este não nos afeta a partir de um conceito. Ele é ente e conta como tal". ${ }^{29}$

Desta forma, Levinas pretende retificar a base e tarefa da ontologia tradicional, inclusive a ontologia heideggeriana que teria promovido a presença do outro à esfera do pensamento, da representação e da apreensão intelectual.

Esta apreensão teórica do outro desqualifica, para Levinas, o elemento de presença fáctica, absoluta, inelutável deste (rosto do) outro, que invoca ao diálogo e a relação.

Perguntar-se-ia a Levinas se sua doutrina não estaria movimentado-se num campo aporético por predicar lingüisticamente a necessidade de fazer aparecer este outro para mim como rosto. A aparente aporia detectada consistiria, creio eu, no fato de a linguagem ser um campo representacional, sincrônico, e a tentativa de fazer aparecer o outro pertenceria ao campo diacrônico.

Este outro, em Levinas, deve poder aparecer aquém, "na", ou além da linguagem? Fica refutada ou, pelo menos, é colocada sob suspeita, a tentativa da ontologia de Heidegger de movimentar-se no território do (puro) pensamento e fabricando, a partir disto, uma compreensão radical da existência humana. Para Levinas, ao contrário, compreender o instrumento não consiste em vê-lo mas em saber manejá-lo; compreender nossa situação no real não é defini-la, mas encontrar-se numa disposição afetiva; compreender o ser é existir. Tudo isto nos indicaria, ao que parece, uma ruptura com a estrutura teorética do pensamento ocidental. Pensar não é mais contemplar, mas engajar-se, estar englobado no que se pensa, estar embarcado - acontecimento dramático do ser-no-mundo. ${ }^{30}$

Para o projeto lacaniano de reconstituição do significado da psicanálise freudiana, a relação primordial do homem não é com o rosto do outro mas com (o sem face do) significante.

O de que se trata, na psicanálise de Lacan, é a produção de elementos possibilitadores da indicação de uma "filosofia lacaniana da ontogênese humana, passível de ser forjada à luz de certa concepção dos efeitos da linguagem sobre o homem". 31

O ponto discordante entre os dois autores, ao que nos parece, é quanto ao estatuto a ser conferido à linguagem e ao significado de sua presença relativamente à instituição do campo humano. O projeto lacaniano insiste na demonstração da eficácia da anterioridade do signo em relação ao humano-ser. Por seu lado, a filosofia levinasiana confere à linguagem um estatuto possibilitador de encontro efetivo com o outro, na medida em que a linguagem operaria como ponte que permitiria a consolidação da relação ao outro.

A partir destas abordagens dissimétricas, ambos os autores ficam confinados a ilhas filosóficas distintas e aparentemente incomunicáveis pois tematizam seus projetos a partir de pensamentos radicalmente distintos em relação a seus conceitos e temas fundamentais.

29 Cf. Lévinas, op. cit., p. 26.

30 Id., p. 23.

31 LEMAIRE, Anika. Introdução à leitura de Lacan. Rio de Janeiro: Campus, 1987, p. 77 


\section{Referências bibliográficas}

BONI, Lamberto (ed.). Enciclopedia de la filosofia Garzanti. Barcelona: BSA, 1992.

CHEMAMA, R. (org.). Dicionánio de psicanálise. Porto Alegre: Artes Médicas, 1995.

HONDERICH, T. (ed.) The Oxford Companion to Philosophy. Oxford/New York: Oxford University Press, 1995.

KAUFMANN, P. Dicionánio enciclopédico de psicanálise. Rio de Janeiro: Zahar, 1996.

LACAN, Jacques. Écrits. Paris: Seuil, 1966.

. Le Seminaire. Livre III. Paris: Seuil, 1981.

LECHTE, John. Fifty Key contemporary thinkers. London/New York: Oxford University Press.

LEMAIRE, Anika. Introdução à leitura de Lacan. Rio: Ed. Campus, 1987.

LEVINAS, E. Ensaios sobre a alteridade. Petrópolis: Ed. Vozes, 1997, p. 22 (Coord. da Tradução: P. Pivatto). 